\title{
Pattern of Pulmonary Function Test in Patients with Severe Mitral Stenosis
}

\author{
Umme Salma Khan ${ }^{1}$, Abdullah- Al- Shafi Majumder ${ }^{2}$, A K M Monwarul Islam³, Fazle Rabbi Mohammed ${ }^{4}$
}

\begin{abstract}
:
Background: The deterioration in lung function in mitral stenosis correlates with the severity of stenotic valves. A correlation is noted between vital capacity and the severity of dyspnoea in patients with mitral stenosis. This study tried to evaluate the pattern of pulmonary function test in patient with severe mitral stenosis.

Materials \& Methods: This study involving 56 patients of severe mitral stenosis was performed in a referral cardiovascular center at Dhaka, Bangladesh from January to September, 2011. Colour doppler echocardiography and pulmonary function test were performed in each cases. Forced vital capacity (FVC), forced expiratory volume in first second (FEV1), FEV1/FVC and peak expiratory flow (PEF) rate was assessed from pulmonary function test. Finally, pattern of pulmonary function test in severe mitral stenosis was assessed.

Results: Amomg 56 patients, 46 were female with a male female ratio 1: 0.22 and the mean age of patients was 28.76 \pm 7.2. Among patients with severe mitral stenosis, mean FEV $(\%)$ was $60.18 \pm 13.054$. Minimum FVC (\%) was 26, maximum was 90 with mean $53.80 \pm 12.313$. The PEF varied from 150 to $330 \mathrm{~L} /$ minute with mean $223.75 \pm 62.3251$. In current study, out of 56 patients, 2 cases had obstructive type and rest of the patients had restricted type of airway on pulmonary function.

Conclusion: The brief results of this study reveal that severe mitral stenosis is associated with impaired pulmonary function, usually presenting restrictive airway pattern.
\end{abstract}

Key words: Pulmonary function test, Mitral stenosis.

\section{Introduction:}

Rheumatic mitral valvular disease is a common and major cause of cardiovascular morbidity and mortality in Bangladesh. ${ }^{1}$ The prevalence of rheumatic heart disease was found to be 1.3 per 1000 for Doppler echocardiography defined rheumatic heart disease. ${ }^{2}$ The most useful descriptor of the severity of mitral valve obstruction is the degree of valve opening in diastole, or the mitral valve orifice area. When the orifice is reduced to $1 \mathrm{~cm}^{2}$ it represents severe mitral stenosis (MS). In severe MS, a left atrioventricular pressure gradient of approximately $20 \mathrm{mmHg}$ is required to maintain normal cardiac output at rest. ${ }^{3}$ Pulmonary venous

1. Dr. Umme Salma Khan, MBBS, MD (Cardiology),

Assistant Professor, Department of Cardiology, Delta Medical College \& Hospital, Mirpur - 1, Dhaka, Bangladesh.

2. Prof. Dr. Abdullah- Al- Shafi Majumder, M.B.BS, D-Card, MD (Cardiology), FACC, FRCP, FESC.

Director and Professor of Cardiology, National Institute of Cardiovascular Diseases, Dhaka, Bangladesh.

3. Dr. A K M Monwarul Islam, MBBS, FCPS, MD (cardiology), FACP, FACC

Registrar, Cardiology

National Institute of Cardiovascular Diseases, Dhaka, Bangladesh.

4. Dr. Fazle Rabbi Mohammed, MBBS, MD (Chest) Specialist, Department of Respiratory Medicine Square Hospitals Ltd, Dhaka, Bangladesh.

\section{Corresponding Author:}

Dr. Umme Salma Khan, MBBS, MD (Cardiology), Assistant Professor, Department of Cardiology, Delta Medical College \& Hospital, Mirpur - 1, Dhaka, Bangladesh. Email: uskhan6@gmail.com. pressure rises with left atrial (LA) pressure increase and is passively associated with an increase in pulmonary arterial pressure. In up to $20 \%$ patients, the pulmonary vascular resistance is also elevated which increases pulmonary artery pressure $^{4}$. The chronic changes in pulmonary circulation cause alterations in pulmonary vessels and in the composition of lung tissue. Accumulation of water, proteins, and proteoglycans in the interstitium has been described in this condition. These interstitial changes are the basis of the clinical manifestations of mitral stenosis and can be detected by pulmonary function tests..$^{5}$ The deterioration in lung function in mitral stenosis correlates with the severity of stenotic valves and the severity of respiratory symptoms. ${ }^{6} \mathrm{~A}$ correlation is noted between vital capacity (VC) and the severity of dyspnoea in patients with mitral stenosis. It was reported that the degree of dyspnoea showed a closer relation to the height of pulmonary artery pressure and to $\mathrm{VC}$, than to maximum breathing capacity in the pure mitral stenosis patients. $^{7}$ This study tried to evaluate the pattern of pulmonary function test (PFT) in patient with severe mitral stenosis.

\section{Material \& Methods:}

This observational study involving 56 patients of severe mitral stenosis was performed in a referral cardiovascular center at Dhaka, Bangladesh from January to September, 2011. Patients with severe mitral stenosis, New York Heart Association (NYHA) class II, III, and IV symptoms and age $<40$ years excluding preexisting obstructive airway diseases and restrictive lung diseases, neurological disability, chest wall deformity, left ventricular ejection fraction $<50 \%$ were included in this study. Colour doppler echocardiography and pulmonary function test (PFT) were performed in each cases. Forced vital capacity (FVC), forced expiratory volume in first 
second (FEV1), FEV1/FVC and peak expiratory flow (PEF) rate was assessed from PFT. PFT was performed according to the American Thoracic Society recommendations. Concomitant mild aortic stenosis was taken under consideration. Obstructive and restrictive lung diseases was excluded by taking history, chest $\mathrm{x}$-ray and pulmonary function test and high resolution computed tomography of chest where needed. Transesophageal echocardiography was performed to exclude the presence of left atrial thrombus in selected patients. Pulmonary arterial systolic pressure was measured. Informed consent was taken from each patient or legal guardian. Data were analyzed by using SPSS 16 .

\section{Results:}

Total 56 patients were enrolled in this study where 46 were female with a male female ratio $1: 0.22$. The mean age of patients was $28.76 \pm 7.2$.

\begin{tabular}{lccc}
\hline \multirow{2}{*}{ Age group } & \multicolumn{2}{c}{ Sex } & \multirow{2}{*}{ Total } \\
\cline { 2 - 3 } & Male & Female & \\
\hline \multirow{2}{*}{$\leq 20$ years } & 2 & 12 & 14 \\
& $3.57 \%$ & $21.43 \%$ & $25 \%$ \\
\hline 20 years & 8 & 34 & 42 \\
\hline Total & $14.29 \%$ & $60.71 \%$ & $75 \%$ \\
\hline Mean \pm SD & 10 & 46 & 56 \\
\hline
\end{tabular}

Table-I. Distribution of the study subjects by age and sex. $(n=56)$

Table-1 shows distribution of the study subjects according to their age and sex. The majority of the respondents were female $46(82.14 \%)$, and the remaining $10(17.86 \%)$ were male. Among the female patients, maximum were in the above 20 year age group ( $n=34,60.71 \%$ of total). The majority of the male subjects ( $\mathrm{n}=8,14.29 \%)$ were above 20 years.

\begin{tabular}{lcc}
\hline Clinical characteristics & Frequency & Percentage \\
\hline Shortness of breath & 56 & 100.0 \\
Palpitation & 17 & 30.4 \\
Cough & 29 & 51.8 \\
Chest pain & 14 & 25.0 \\
Paroxysmal nocturnal & 17 & 30.4 \\
dyspnea (PND) & & \\
Haemoptysis & 0 & 0.0 \\
Orthopnoea & 2 & 3.6 \\
History of rheumatic fever & 31 & 55.4 \\
Rheumatic fever prophylaxis & 26 & 46.4 \\
\hline
\end{tabular}

Table II. Distribution of patients by baseline clinical characteristics $(\mathrm{n}=56)$

Table II shows that all the patients $(n=56,100 \%)$ had shortness of breath. Other symptoms were cough $(n=29,51.8 \%)$, chest pain, PND, orthopnoea etc. Majority (55.4\%) had history of rheumatic fever. Among the 56 subjects, 26 (46.4\%) took prophylaxis against rheumatic fever.

\begin{tabular}{lccc}
\hline $\begin{array}{l}\text { Pulmonary } \\
\text { function. } \\
\text { test }\end{array}$ & $\begin{array}{c}\text { Minimum } \\
\text { (\% of predicted } \\
\text { value) }\end{array}$ & $\begin{array}{c}\text { Maximum } \\
\text { (\% predicted } \\
\text { value) }\end{array}$ & Mean \pm SD \\
\hline $\mathrm{FEV}_{1}$ & 30 & 88 & $60.18 \pm 13.054$ \\
$\mathrm{FVC}$ & 26 & 90 & $53.80 \pm 12.313$ \\
$\mathrm{FEV}_{1} / \mathrm{FVC}$ & 45 & 137 & $112.64 \pm 16.292$ \\
$\mathrm{PEF}(\mathrm{L} / \mathrm{min})$ & 150 & 330 & $223.75 \pm 62.3251$ \\
\hline
\end{tabular}

Table III. Distribution of patients by pulmonary function test $(\mathrm{n}=56)$

Table III depicts the lung function test results. Mean FEV (\%) was $60.18 \pm 13.054$. Minimum FVC (\%) was 26, maximum was 90 and mean FVC was $53.80 \pm 12.313$. The $\mathrm{PEF}$ varied from 150 to $330 \mathrm{~L} /$ minute with mean $223.75 \pm$ 62.3251. In current study, out of 56 non-smoker patients, 2 cases had obstructive type and rest of the patients had restricted type of features on pulmonary function.

\section{Discussion:}

Pulmonary congestion is a major complication of left sided heart disease as well as left ventricular dysfunction and an important risk factor for hospitalization. ${ }^{8}$ Several reports show that in left sided heart causes, even if clinically stable, subclinical pulmonary oedema accounts for some morphological changes that often result in well-defined clinical correlates, such as obstructive and restrictive abnormalities in lung function, increased bronchial responsiveness and impaired gas exchange across the alveolar capillary. ${ }^{9,10}$

Many patients of mitral stenosis present with respiratory symptoms, and are often treated as bronchial asthma or chronic obstructive airway disease. Impaired pulmonary function may be an important contributor to over all morbidity and mortality in our country, where the patients often present late. Here lies the rationale of the present study.

Fifty-six patients with severe mitral stenosis were enrolled in this study. The mean age of this study subject $(28.76 \pm 7.2)$ differed from the study done by Simkova and Urbanova in 2001. ${ }^{11}$ A comprehensive study by Yoshioka in 1990 showed age range from 31 to 71 years. ${ }^{12}$ In current study the mean population age is much younger than the other studies. In the present study male and female ratio (1: 0.22) differed from a study performed by Yoshioka . ${ }^{12}$ They showed male dominance where as a female preponderance was observed in the current study.

In current study, out of 56 non-smoker patients, 2 cases had obstructive type and rest of the patients had restricted type of features on pulmonary function. Yoshioka et al. (1990) and Joan et al. (2000) noticed mostly obstructive pattern of pulmonary function. ${ }^{12,5}$ The restrictive features which are encountered in the chronic stages of lung congestion are attributed to increased interstitial fluid, increased pulmonary 
blood volume, muscle fatigue, decreased lung compliance, and fibrosis from chronic congestion. ${ }^{8}$ In a study by Light et al. in 1983 found both obstructive and restrictive type of leison on pulmonary function test in patients with congestive heart failure. ${ }^{13}$ In another study by Simkova and Urbanova (2001) found restrictive as well as obstructive ventilatory disturbance in patients with mitral stenosis. ${ }^{11}$ It has been speculated that weakness of the chest wall muscle limits the ability of the patients to perform the maximum expiration. Yoshioka showed all of his patients got improvement on greater part of their ventilatory function which is due to alteration of reversible pulmonary haemodynamics.

\section{Conclusion:}

Majority of the patients with severe Mitral stenosis demonstrated a pulmonary function limitation of restrictive type. As the respiratory symptoms are most common presenting feature of these patients, the knowledge about the pattern of limitation would help to understand the pathology better. The degree of valvular pathology correlated to PFT limitation and pattern may shed further light on the point of change in the lung pathology from a reversible to an irreversible stage. The proper timing of intervention may be also aided by the assessment of PFT. Further research is need in this field.

\section{References:}

1. Islam MN, Khan LA, Mohibullah AKM. Clinical profile of rheumatic heart disease in Bangladesh. Bang Med J 1987; 16: 6-17.

2. Ahmed J, Zaman MM, Hasan MMM. Prevalence of rheumatic fever and rheumatic heart disease in rural Bangladesh. Tropical Doctor $2005 ; 35(3): 160-161$
3. Otto CM, Bonow RO. Valvular Heart disease: Mitral stenosis. In: Braunwald Heart Disease. $8^{\text {th }}$ ed. Philadelphia: Saunders; 2008.

4. Rahimtoola SH. In: Hurst's the Heart. $12^{\text {th }}$ ed. New York: McGraw Hill Medical; 2008.

5. Gómez-Hospital AJ, Cequier A, Romaro PV, Canete C, Ugartemendia C, Mauri J, Esplugas E. Partial improvement in pulmonary function after successful percutaneous balloon mitral valvotomy. Chest 2000; 117: 643-648.

6. Nour MM, Shuhaiber H, Yousof AM. Lung Function and Severity of Mitral Stenosis. Medical Principles and Practice 1999; 8: 32-39.

7. Cosby RS, StowelI JR, Hartwig WR, Mayo M. Abnormal ventilatory patterns in mitral stenosis. Chest 1956; 29:633-640.

8. Guzzi M, Pontone G, Brambilla R, Agostoni P, Reina G. Alveolar Capillary membrane gas conductance: A novel prognostic indicator in chronic heart failure. Eur Heart J 2002; 23(6): 467 - 476.

9. Kraemer MD, Kubo SH, Rector TS, Brunsvold N, Bank AJ. Pulmonary and peripheral vascular factors are important determinants of peak exercise oxygen uptake in patients with heart failure. J Am Coll Cardiol 1993; 22: 641-648.

10. Sullivan MJ, Higgimbotham MB, Cobb FR. Increased exercise ventilation in patients with chronic heart failure: intact ventilatory control despite hemodynamic and pulmonary abnormalities. Circulation 1988; 77: 552-559.

11. Simkova I, Urbanova J. Pulmonary function alteration after correction of mitral stenosis, Brastisl Lek listy 2001; 102: 32-39.

12. Yoshioka T, Nakanishi N, Okubo S, Konieda T, Ishikura F, Nagata $\mathrm{S}$. Improvement of pulmonary function in mitral stenosis after percutaneous transvenous mitral commussirotomy. Chest 1990; 98 : 290-294.

13. Light WR, George RB. Serial Pulmonary Function in Patients With Acute Heart Failure. Arch Intern Med 1983; 143(3): 429-433. 